\title{
US/Soviet proposal to ban nuclear power in Earth orbit
}

\section{Berkeley}

THE impending fall of Cosmos 1900 (see right) promises to draw attention to a joint proposal by US and Soviet scientists to ban nuclear power in Earth orbit.

The plan, proposed by the Federation of American Scientists (FAS) and the Committee of Soviet Scientists Against the Nuclear Threat, led by Roald Sagdeev, soon to leave his post as director of the Soviet Space Research Institute, would serve two purposes: to end the environmental hazard of radioactivity raining down from orbit; and to curtail an impending arms race in space. Verification of compliance with such a ban would be straightforward, the scientists detected with infrared, gamma and neutron radiation. And the ban would not prohibit nuclear powered deep-space exploratory or scientific missions.

The United States has not launched a nuclear-powered spacecraft since the Voyager probes in 1977, but is developing a new generation of nuclear reactors, for use in the Strategic Defense Initiative (SDI) as well as other applications. Although the Reagan administration promised the US public that SDI would be "non-nuclear", there is some confusion over whether that pledge refers only to nuclear weapons or to power as well. Most experts agree that the directed-energy weapons proposed for SDI will not be possible without long-lived, manoeuvrable and radiation-tolerant nuclear reactors, and that orbiting nuclear power stations are necessary for most military applications in space.

If Cosmos 1900 had to fall, it picked a fortuitous time, says Steven Aftergood, director of the Committee to Bridge the Gap, a Los Angeles-based public interest research organization opposed to nuclear space technology. "It will provide a useful illustration of at least some of the hazards say, as nuclear reactors can be readily

involved", he said. But environmental concerns alone are not enough to justify a ban on orbiting reactors, says Aftergood, who helped to draft the proposed ban.

The re-entry problem could be largely solved if both superpowers agreed to orbit reactors only above a minimum safe altitude. Launch failures are not a hazard with fission reactors as they are with plutonium-powered radioactive thermoelectric generators (RTGs), as uranium itself is not particularly hazardous, and fission is not initiated until the reactors are

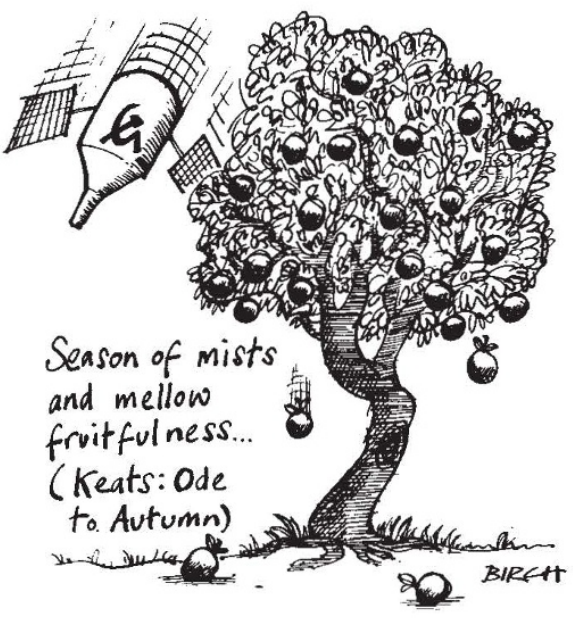

in place in orbit. Moreover, the ban, as proposed, would still allow deep-space missions to carry RTGs, whose highly radioactive plutonium does present a launch hazard.

Although a nuclear reactor ban would require the Soviets to redesign their RORSAT system, there is nevertheless optimism among the scientists that Sagdeev will win the support of Soviet officials for the ban. Congress has also shown interest, even though the ban would imply the end of SDI. The plan may be the subject of committee hearings in the next few months. Marcia Barinaga

\section{Rights of patients to immortalized cells}

\section{Washington}

A SURPRISE ruling by a Californian court backs the notion that patients have the right to control what happens to samples of tissue and body fluids taken from them, and have a financial interest in any products developed from them.

The case arose after a Seattle businessman, John Moore, filed a suit against the University of California at Los Angeles (UCLA) Medical Center where he had been succesfully treated for hairy-cell leukaemia. Cells from his spleen, which was removed as a standard part of his treatment, were found to have unique properties that made them useful as a cell-culture source of interferons and colony-stimulating factor. UCLA researchers established a cell line from the spleen cells which the university then patented and developed in collaboration with two biotechnology companies.

The case may continue for years and eventually be appealed in the Supreme Court of California. In the interim, biotechnology companies will have to prepare themselves for the possibility that they will have to share profits from cell lines with the patients who provided the cells.

\section{Failed satellite to crash soon}

\section{Berkeley}

THE third Soviet nuclear-powered satellite to fall from orbit will re-enter the atmosphere in August or September. The Soviets have lost radio contact with Cosmos 1900, a radar ocean reconnaissance satellite (RORSAT), preventing boost of the satellite to a stable high-altitude orbit, and ensuring that it will return to Earth, as its orbit continues to decay.

The low orbits (around $250 \mathrm{~km}$ ) of the RORSATs make them vulnerable to reentry into the atmosphere, and also dependent on nuclear power, as the large surface area of solar panels would create intolerable drag. After the satellites' brief functional life of several months, they are normally boosted to an orbit of close to $1,000 \mathrm{~km}$, where they will remain for at least 300 years, long enough to allow the decay of most of their fission products.

Cosmos 1900 is the latest in a more than 20 year sequence of failures by US and Soviet nuclear satellites. Two previous RORSATs have re-entered the atmosphere. In 1978, Cosmos 954 scattered radioactive debris over $100,000 \mathrm{~km}^{2}$ in northwestern Canada, and in 1983 a similar incident was avoided when the Soviets disengaged the reactor of the re-entering Cosmos 1402, allowing it to burn up on entry and disperse its radioactivity throughout the atmosphere.

The United States has had its share of nuclear satellite failures as well. Most of the 23 US nuclear-powered space missions have used radioisotope thermoelectric generators (RTGs), in which highly radioactive plutonium-238 generates thermal energy. In 1964, the aborted launch of a navigational satellite released 17,000 curies of plutonium-238 into the atmosphere. Three RTGs from aborted missions have been lost in the Pacific Ocean. Two were recovered, undamaged, but one, from the lunar probe aboard Apollo 13 , has sunk irretrievably.

Whether the radioactive core of Cosmos 1900 will reach the Earth remains uncertain. The Soviets have suggested they may be able to disengage the core, but Western observers are sceptical, as radio contact with the craft has been lost. Current estimates suggest the satellite will come down in late September, but it could be brought down sooner by increased solar activity, which causes expansion of the Earth's atmosphere, or by loss of altitude control, which would result in uncontrolled tumbling. The satellite's orbital inclination of $65^{\circ}$ takes it over virtually all inhabited parts of the globe, and it will not be possible until a day or so before its re-entry to determine the path of its fall. 